\title{
A case-control study to evaluate risk factors for ectopic pregnancy
}

\section{Sangita Khedar, Premlata Mital*, Lata Rajoria, Divya Gupta, Usha Shekhawat, Sunita Singhal}

Department of Obstetrics and Gynaecology, SMS Medical College, Jaipur, Rajasthan, India

Received: 26 June 2016

Accepted: 12 July 2016

\author{
*Correspondence: \\ Dr. Premlata Mital, \\ E-mail: drpremlatamital@gmail.com
}

Copyright: (C) the author(s), publisher and licensee Medip Academy. This is an open-access article distributed under the terms of the Creative Commons Attribution Non-Commercial License, which permits unrestricted non-commercial use, distribution, and reproduction in any medium, provided the original work is properly cited.

\section{ABSTRACT}

Background: Morbidity and mortality associated with ectopic pregnancy are directly related to the length of time required for diagnosis. Knowledge of risk factors for ectopic pregnancy will help an obstetrician to suspect and diagnose the condition early. Therefore, the present study was designed to identify potential risk factors and to evaluate the contribution of the risk factors in ectopic pregnancy.

Methods: Study population consists of 65 women with ectopic pregnancy and for each ectopic case one woman with first trimester intrauterine pregnancy was recruited as control. Data were retrieved from all through a structured proforma. Data were analyzed statistically.

Results: Various significant risk factors for ectopic pregnancy found were pelvic inflammatory disease, tubal ligation, age above $30 \mathrm{yrs}$, previous use of IUCD, low socio-economic status, tubal infertility and genital tuberculosis while no significant association was seen with smoking, age below 30 years, history of prior induced abortion, oral contraceptive pills and clomiphene citrate.

Conclusions: Increase awareness and knowledge of risk factors will help obstetricians to suspect and diagnose ectopic pregnancy early and accurately and enable them to plan medical treatment. Surgical treatment will be reserved for ruptured ectopic pregnancy and haemodynamically unstable patients.

Keywords: Ectopic pregnancy, Risk factors, Pelvic inflammatory disease, Tubal ligation

\section{INTRODUCTION}

Ectopic pregnancy (EP) is the leading cause of maternal death during the first trimester of pregnancy, accounting for approximately $10 \%$ of all pregnancy-related deaths. ${ }^{1}$ It still remains a serious health problem for women of childbearing age. ${ }^{2}$ A ruptured ectopic pregnancy is a true medical emergency. Morbidity due to ectopic pregnancy is in the form of infertility and ectopic recurrence. ${ }^{3}$

Although the total number of intrauterine pregnancies has declined over the past three decades, there has been a rise in the incidence of ectopic pregnancy as a result of an increased and persistent exposure to its risk factors and partially due to improved ability in making an earlier diagnosis. $^{4,5}$
As the morbidity and mortality associated with extrauterine pregnancy are directly related to the length of time required for diagnosis, the increased awareness and knowledge of the risk factors for it could enable an early and accurate diagnosis of the disease, resulting in earlier intervention.

Numerous studies have been done to explore the risk factors for ectopic pregnancy and it was found that the main risk factors for ectopic pregnancy are conditions or procedures which cause tubal damage. The exact role and strength of these factors have not been definitively determined. Very few studies have been done in our state to find various risk factors for ectopic pregnancy therefore; the present study was designed to identify potential risk factors and to evaluate their contribution in ectopic pregnancy. 


\section{METHODS}

The present study was a hospital based prospective case control study conducted in the Department of Obstetrics and Gynaecology, from May 2014 to November 2015.

Sample size was calculated as 63 subjects at $\alpha$ error 0.5 and power $80 \%$ assuming 5.4 odds ratio and $6 \%$ prevalence of pelvic inflammatory disease which was enhanced to 65 Study populations consists of 65 cases of ectopic pregnancy. Only those patients who had established diagnosis of ectopic pregnancy were included as cases. For each case of ectopic pregnancy, one control i.e. woman with first trimester intrauterine pregnancy was included in the study. The information was collected from each woman (from interview and medical records) which included sociodemographic characteristics; gynaecologic, reproductive, and surgical history; conditions at conception (use of contraception, ovulation induction); smoking habits; history of pelvic inflammatory disease. Data were analysed statistically. Univariate analysis was done to find out crude odds ratios $(\mathrm{OR})$ and $\mathrm{p}$ value. Significance level was set at $\mathrm{P}<0.05$.

\section{RESULTS}

Socio-demographic characteristics and cigarette smoking (Table 1)

Overall, the mean age of the cases was significantly higher than that of the controls $(28 \pm 5.16 \mathrm{yrs}$ v/s $24.6 \pm$ $2.75 \mathrm{yrs})$. The crude risk of ectopic pregnancy increased with age. The high risk of ectopic pregnancy is in age group 30-34 yrs and it was statistically significant (OR 7.4; $95 \%$ CI (1.96- 28.001); P-value $=0.003)$.

Table 1: Ectopic pregnancy and socio-demographic characteristics: crude odds ratios (OR) and 95 percent confidence intervals $(\mathbf{C I})$.

\begin{tabular}{|c|c|c|c|c|c|c|c|}
\hline \multirow{2}{*}{ Variables } & \multicolumn{2}{|c|}{ Cases } & \multicolumn{2}{|c|}{ Controls } & \multirow{2}{*}{ OR } & \multirow{2}{*}{ CI } & \multirow{2}{*}{$\mathbf{P}$} \\
\hline & No. & $\%$ & No. & $\%$ & & & \\
\hline \multicolumn{8}{|c|}{ Age Group (in yrs) } \\
\hline$<20$ & 1 & 1.54 & 1 & 1.54 & 1.308 & $0.078-21.906$ & $0.59, \mathrm{NS}$ \\
\hline $20-24$ & 13 & 20.00 & 27 & 41.54 & 0.629 & $0.273-1.453$ & $0.37, \mathrm{NS}$ \\
\hline $25-29$ & 26 & 40.00 & 34 & 52.30 & 1 & & \\
\hline $30-34$ & 17 & 26.15 & 3 & 4.62 & 7.410 & $1.961-28.001$ & 0.003,Sig \\
\hline $35-39$ & 5 & 7.69 & 0 & 0.00 & $*$ & $*$ & 0.049,Sig \\
\hline$\geq 40$ & 3 & 4.62 & 0 & 0.00 & $*$ & $*$ & $0.18, \mathrm{NS}$ \\
\hline Mean Age & \multicolumn{2}{|c|}{$28.06 \pm 5.16$} & \multicolumn{2}{|c|}{$24.60 \pm 2.75$} & & & $<0.001$, Sig \\
\hline \multicolumn{8}{|l|}{ Religion } \\
\hline Hindu & 59 & 90.77 & 51 & 78.46 & \multirow{2}{*}{2.699} & \multirow{2}{*}{$0.966-7.540$} & \multirow{2}{*}{$0.089, \mathrm{NS}$} \\
\hline Muslim & 6 & 9.23 & 14 & 21.54 & & & \\
\hline \multicolumn{8}{|l|}{ Residence } \\
\hline Rural & 35 & 53.85 & 10 & 15.38 & \multirow{2}{*}{6.417} & \multirow{2}{*}{$2.793-14.741$} & \multirow{2}{*}{$<0.001$,Sig } \\
\hline Urban & 30 & 46.15 & 55 & 84.62 & & & \\
\hline \\
\hline & \multicolumn{7}{|c|}{ Status } \\
\hline Lower & 25 & 38.46 & 13 & 20.00 & 2.581 & \multirow[t]{2}{*}{$1.170-5.692$} & \multirow[t]{2}{*}{ 0.029,Sig } \\
\hline Middle & 38 & 58.46 & 51 & 78.46 & 1 & & \\
\hline Upper & 2 & 3.08 & 1 & 1.54 & 2.684 & $0.235-30.703$ & $0.82, \mathrm{NS}$ \\
\hline \multicolumn{8}{|l|}{ Smoking } \\
\hline Yes & 2 & 3.08 & 1 & 1.54 & \multirow{2}{*}{2.032} & \multirow{2}{*}{$0.180-22.97$} & \multirow{2}{*}{$1.0, \mathrm{NS}$} \\
\hline No & 63 & 96.92 & 64 & 98.46 & & & \\
\hline
\end{tabular}

Cannot compute odd ratio with 0 value in table

Low socio-economic status was found as a risk factor for ectopic pregnancy (OR 2.58; CI 1.170-5.692; $\mathrm{P}=0.03$ ). Other socio-demographic characteristics had no association with ectopic pregnancy. The crude OR for smoking was 2.032 but statistically no significant association was found between smoking and ectopic pregnancy.

\section{Gynaecological and obstetric history and surgical history (Table 2)}

In present study $35.4 \%$ cases and $40 \%$ controls were nulliparous. On univariate analysis the risk of ectopic pregnancy increases with increasing parity. Risk of ectopic pregnancy was 1.5 times more in para 2 (OR 
1.46; CI .628-3.408; $\mathrm{P}=.50$ ) but statistically not significant which significantly increases to 10 folds in para $\geq 3$. (OR: 10.17; CI: 1.196-86.546; $\mathrm{P}=0.032$ ).

Past history of ectopic pregnancy was reported in $7.7 \%$ of cases and $1.5 \%$ of controls. Out of 5 cases, 1 had history of two ectopic pregnancies. On univariate analysis crude OR was 5.333 (CI: 0.605-46.981 and P-value $=0.21$ ) which was statistically not significant.

In our study it was observed that higher proportion of cases had history of spontaneous abortions $(23.1 \%)$ as compared to pregnant controls (4.6\%) which is statistically significant (P-value <0.05) and we found a dose-response relation with number of prior spontaneous abortions and ectopic pregnancy.

In present study it was observed that $6.2 \%$ of cases and $1.5 \%$ of controls had history of induced abortion. Out of 4 cases, 2 had history of two induced abortion. In present study, no significant association was found between induced abortion and ectopic pregnancy.

Table 2: Ectopic pregnancy and gynaecological, obstetric history and surgical history: crude odds ratios (OR) and 95 percent confidence intervals $(\mathrm{CI})$.

\begin{tabular}{|c|c|c|c|c|c|c|c|}
\hline \multirow{2}{*}{ Variables } & \multicolumn{2}{|c|}{ Cases } & \multicolumn{2}{|c|}{ Controls } & \multirow{2}{*}{ OR } & \multirow[b]{2}{*}{ CI } & \multirow[b]{2}{*}{$\mathbf{p}$} \\
\hline & No. & $\%$ & No. & $\%$ & & & \\
\hline \multicolumn{8}{|c|}{ Prior Deliveries } \\
\hline None & 23 & 35.38 & 26 & 40.00 & 1 & & \\
\hline 1 & 11 & 16.92 & 21 & 32.31 & 0.592 & $0.236-1.486$ & $0.37, \mathrm{NS}$ \\
\hline 2 & 22 & 33.85 & 17 & 26.15 & 1.463 & $0.628-3.408$ & $0.50, \mathrm{NS}$ \\
\hline$\geq 3$ & 9 & 13.85 & 1 & 1.54 & 10.174 & $1.196-86.546$ & 0.03, Sig \\
\hline \multicolumn{8}{|c|}{$\begin{array}{l}\text { Prior ectopic } \\
\text { pregnancies }\end{array}$} \\
\hline None & 60 & 92.31 & 64 & 98.46 & 1 & \multirow{3}{*}{$0.464-39.264$} & \\
\hline 1 & 4 & 6.15 & 1 & 1.54 & 4.267 & & $0.35, \mathrm{NS}$ \\
\hline$\geq 2$ & 1 & 1.54 & 0 & 0 & $*$ & & $0.98, \mathrm{NS}$ \\
\hline \multicolumn{8}{|c|}{$\begin{array}{l}\text { Prior spontaneous } \\
\text { abortions }\end{array}$} \\
\hline None & 50 & 76.92 & 62 & 95.38 & 1 & & \\
\hline 1 & 6 & 9.23 & 2 & 3.2 & 3.72 & $0.719-19.237$ & $0.19, \mathrm{NS}$ \\
\hline$\geq 2$ & 9 & 13.85 & 1 & 1.5 & 11.16 & $1.368-91.075$ & $0.02, \mathrm{NS}$ \\
\hline \multicolumn{8}{|c|}{$\begin{array}{l}\text { Prior induced } \\
\text { abortions }\end{array}$} \\
\hline None & 61 & 93.85 & 64 & 98.46 & 1 & \multirow{3}{*}{$0.185-23.740$} & \multirow{3}{*}{$\begin{array}{l}0.97, \mathrm{NS} \\
0.49, \mathrm{NS}\end{array}$} \\
\hline 1 & 2 & 3.07 & 1 & 1.54 & 2.1 & & \\
\hline$\geq 2$ & 2 & 3.07 & 0 & 0.0 & $*$ & & \\
\hline \multicolumn{8}{|c|}{ Appendectomy } \\
\hline $\begin{array}{l}\text { Yes } \\
\text { No }\end{array}$ & $\begin{array}{c}3 \\
62\end{array}$ & $\begin{array}{c}4.62 \\
95.38\end{array}$ & $\begin{array}{c}2 \\
63\end{array}$ & $\begin{array}{c}3.08 \\
96.92\end{array}$ & 1.524 & $0.246-9.438$ & $1.0, \mathrm{NS}$ \\
\hline \multicolumn{8}{|c|}{ Prior tubal surgery } \\
\hline Yes & 20 & 30.76 & 2 & 3.07 & & & \\
\hline No & 45 & 69.24 & 63 & 96.93 & 14 & $3.114-62.937$ & $<0.0001 \mathrm{Sig}$ \\
\hline \multicolumn{8}{|c|}{$\begin{array}{l}\text { Previous Caesarean } \\
\text { Section }\end{array}$} \\
\hline No & 57 & 87.69 & 58 & 89.23 & 1 & & \multirow{3}{*}{$\begin{array}{l}1.0, \mathrm{NS} \\
0.7, \mathrm{NS}\end{array}$} \\
\hline 1 & 4 & 6.15 & 3 & 4.62 & 1.357 & $0.291-6.335$ & \\
\hline$\geq 2$ & 4 & 6.15 & 4 & 6.15 & 1.018 & $0.243-4.266$ & \\
\hline \multicolumn{8}{|c|}{$\begin{array}{l}\text { Previous } \mathrm{D} \text { and } \mathrm{C} \text { and } \\
\mathrm{D} \text { and } \mathrm{E}\end{array}$} \\
\hline No & 51 & 78.46 & 60 & 92.31 & 1 & & \multirow{2}{*}{ 0.04,Sig } \\
\hline Yes & 14 & 21.54 & 5 & 7.69 & 3.294 & $1.111-9.771$ & \\
\hline
\end{tabular}

Cannot compute odd ratio with 0 value in table 
History of previous surgery in the form of appendicectomy was present in $4.6 \%$ cases and $3.08 \%$ controls, tubal surgery in $30.76 \%$ cases and $3.07 \%$ controls, LSCS in $12.3 \%$ cases and $10.8 \%$ controls and. $\mathrm{D}$ and $\mathrm{C}$ or $\mathrm{D}$ and $\mathrm{E}$ in $21.5 \%$ cases and $7.69 \%$ controls.

Table 3: Ectopic pregnancy and infectious history: crude odds ratios (OR) and 95 percent confidence intervals (CI).

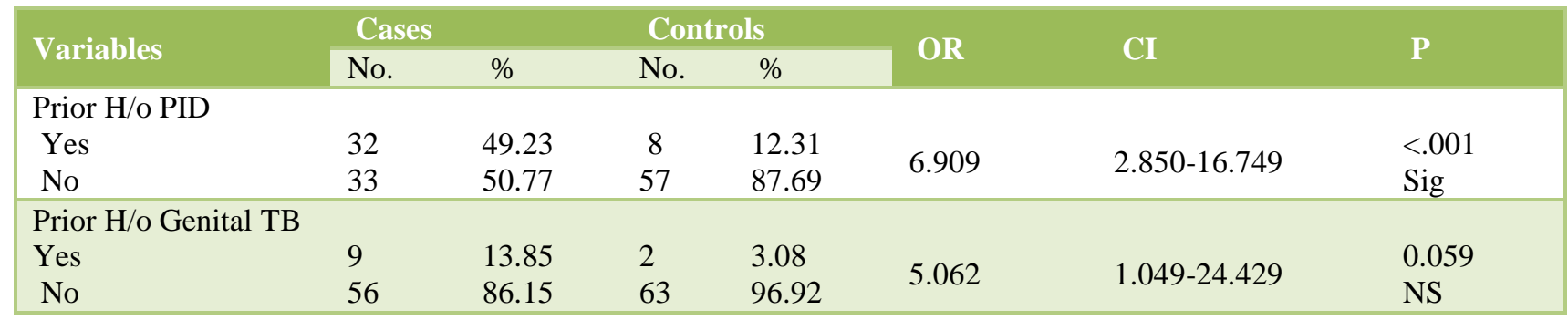

Table 4: Ectopic pregnancy, contraceptive history and fertility markers: crude odds ratios (OR) and 95 percent confidence intervals $(\mathbf{C I})$.

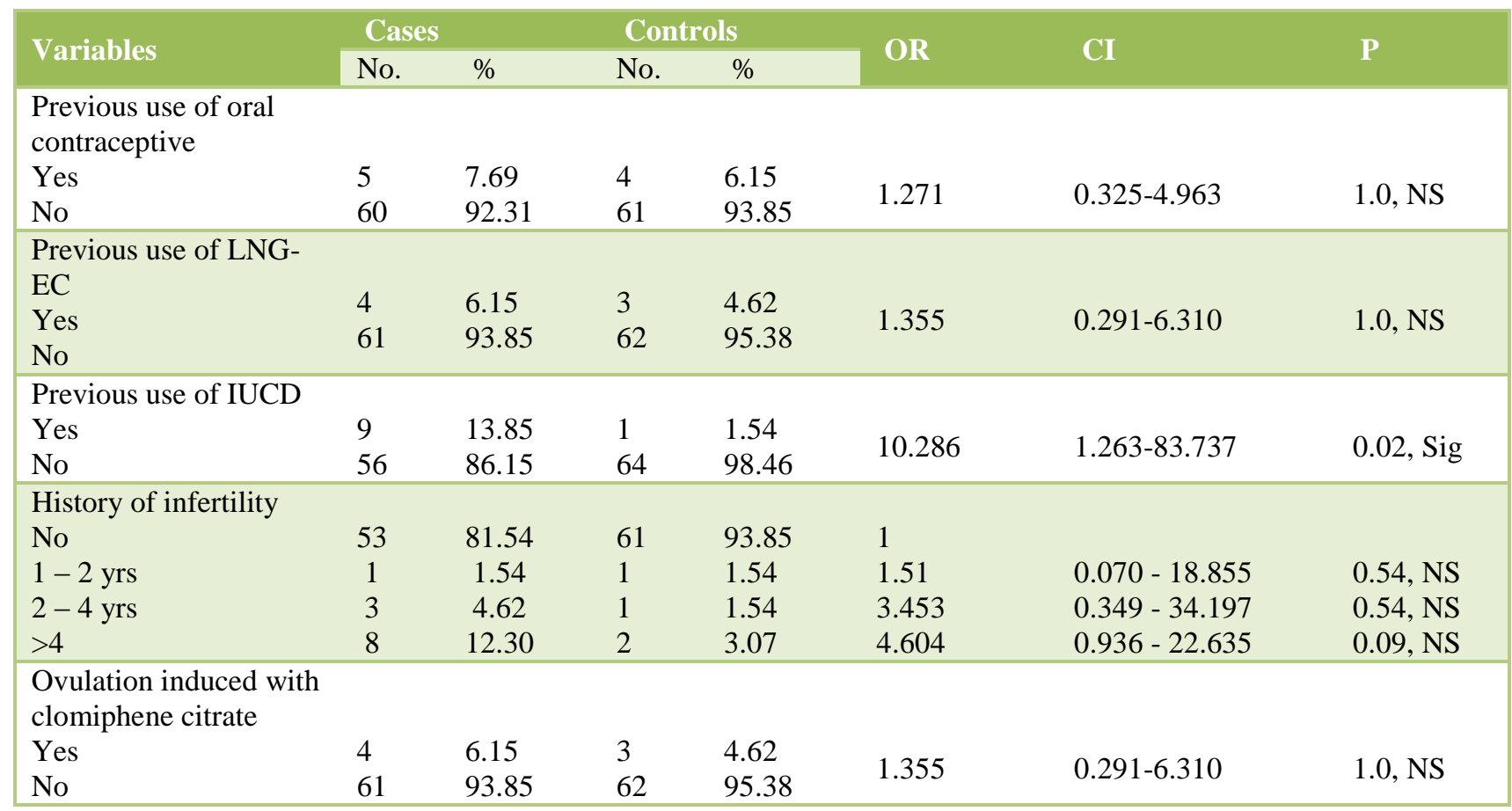

On univariate analysis only prior tubal surgery was significantly associated with ectopic pregnancy [OR 14, CI 3.114-62.937, p value $<0.0001]$.

\section{Ectopic pregnancy and infectious history (Table 3)}

$49.2 \%$ of cases and $12.3 \%$ of controls had history of PID. On univariate analysis, crude OR is 6.9 with CI: $2.850-$ 16.748, $\mathrm{P}<.001$ which shows statistically significant relation of PID with ectopic pregnancy. As evident from the table, $13.8 \%$ cases and $3.6 \%$ controls had history of prior genital tuberculosis. On univariate analysis, association between prior genital tuberculosis and ectopic pregnancy was found to be nearly significant (Crude OR: 5.06, CI: 1.049-24.429, P-value = 0.059).

\section{Ectopic pregnancy, contraceptive history and fertility markers (Table 4)}

As evident from above table, $6.15 \%$ cases and $4.62 \%$ controls had used LNG-EC pills and $7.69 \%$ cases and $6.15 \%$ controls had history of previous use of OCP. No association was found between previous use of contraceptive pills and risk of ectopic pregnancy (LNG- 
EC: $\quad \mathrm{OR}=1.355,95 \%$ CI: $.291-6.310$ and OCPs: $\mathrm{OR}=1.271,95 \% \mathrm{CI}: .325-4.963 ; \mathrm{P}=1.0)$.

$13.85 \%$ cases and $1.54 \%$ controls had history of previous IUCD use. On univariate analysis, previous use of intrauterine device (IUD) was associated with 10 fold increased risk of ectopic pregnancy.

Only $18.46 \%$ cases and $6.15 \%$ controls had history of infertility of variable duration. On univariate analysis, it was observed that with increase in duration of infertility the crude risk for ectopic pregnancy increases. For 1-2 yrs of infertility crude risk was 1.2, for 2-4 yrs crude risk was 3 and for $>4$ yrs duration of infertility crude risk is 4.6, although statistically the risk was not significant.

$6.15 \%$ cases and $4.62 \%$ controls had history of ovulation induction with clomiphene citrate. On univariate analysis, it was observed that the risk of ectopic pregnancy with clomiphene citrate was statistically not significant (OR 1.355, CI 0.291-6.310, p value 1.0).

Table 5: Summary of contribution of risk factors for ectopic pregnancy with statistical significance.

\begin{tabular}{|c|c|c|}
\hline Risk Factors & OR (95\% CI) & P-value \\
\hline Tubal Ligation & $\begin{array}{l}12.064(2.668- \\
54.553)\end{array}$ & $\begin{array}{l}<0.001, \\
\text { Sig }\end{array}$ \\
\hline $\begin{array}{l}\text { Pelvic inflammatory } \\
\text { disease }\end{array}$ & $\begin{array}{l}6.909(2.850- \\
16.749)\end{array}$ & $\begin{array}{l}<0.001 \\
\text { Sig }\end{array}$ \\
\hline Age above 30 yrs & $\begin{array}{l}7.4(1.961- \\
28.001)\end{array}$ & $\begin{array}{l}0.003 \\
\text { Sig }\end{array}$ \\
\hline $\begin{array}{l}\text { Prior spontaneous } \\
\text { abortion }\end{array}$ & $\begin{array}{l}6.2(1.699- \\
22.622)\end{array}$ & $\begin{array}{l}0.005 \\
\text { Sig }\end{array}$ \\
\hline Previous Use of IUCD & $\begin{array}{l}10.286(1.263- \\
83.737)\end{array}$ & $\begin{array}{l}0.021 \\
\text { Sig }\end{array}$ \\
\hline Tubal infertility & $\begin{array}{l}9.21(1.115- \\
76.039)\end{array}$ & $\begin{array}{l}0.035 \\
\text { Sig }\end{array}$ \\
\hline Genital tuberculosis & $\begin{array}{l}5.06(1.049- \\
24.429)\end{array}$ & $\begin{array}{l}0.059 \\
\text { Sig }\end{array}$ \\
\hline $\mathrm{D}$ and $\mathrm{C}$ and $\mathrm{D}$ and $\mathrm{E}$ & $\begin{array}{l}3.29(1.111- \\
9.771)\end{array}$ & $\begin{array}{l}0.047 \\
\text { Sig }\end{array}$ \\
\hline $\begin{array}{l}\text { Low socio-economic } \\
\text { status }\end{array}$ & $\begin{array}{l}2.581(1.170- \\
5.692)\end{array}$ & $\begin{array}{l}0.029 \\
\text { Sig }\end{array}$ \\
\hline Appendicectomy & $\begin{array}{l}1.524(0.246- \\
9.438)\end{array}$ & $1.0, \mathrm{NS}$ \\
\hline $\begin{array}{l}\text { Previous caesarean } \\
\text { section }\end{array}$ & $\begin{array}{l}1.163(0.396- \\
3.418)\end{array}$ & $1.0, \mathrm{NS}$ \\
\hline $\begin{array}{l}\text { Ovulation with } \\
\text { clomiphene citrate }\end{array}$ & $\begin{array}{l}1.355(0.291- \\
6.310)\end{array}$ & $1.0, \mathrm{NS}$ \\
\hline Smoking & $\begin{array}{l}2.032(0.180- \\
22.97)\end{array}$ & 1.0,NS \\
\hline
\end{tabular}

\section{Contribution of risk factors for ectopic pregnancy with statistical significance (Table 5)}

Association of tubal Ligation, pelvic Inflammatory disease, age above 30 yrs and prior spontaneous abortion was highly significant with $\mathrm{p}$ value of $<0.001,<0.001$,
$<0.003$ and $<0.005$ respectively. Previous use of IUCD, tubal infertility, Genital Tuberculosis, D\&C and D\&E and Low Socio-economic Status were significant risk factors for ectopic pregnancy ( $p$ value $<0.05$ ) while no significant risk for ectopic pregnancy was seen with history of appendicectomy, previous caesarean section, ovulation with Clomiphene citrate and smoking ( $\mathrm{p}$ value $1.0)$.

\section{DISCUSSION}

In present study, the average maternal age for women with ectopic pregnancy and control group was $28 \pm 5.16$ yrs (range 19-44 yrs) and 24.6 \pm 2.75 yrs (range 19-32 yrs) respectively and it was found statistically significant $(\mathrm{P}$ $<0.001)$. This is supported by ICMR task force project, Pradhan $\mathrm{P}$ et al and Parashi $\mathrm{S}$ et al studies, where the mean age of ectopic was 28, 30.1 and 28.7 yrs respectively. ${ }^{6-8}$ Moini A et al found that the average maternal age was significantly higher for women with ectopic pregnancy than controls $(30.3 \pm 5 \mathrm{v} / \mathrm{s} 27.1 \pm 5.3 ; \mathrm{P}$ $<0.0001){ }^{9}$ The high incidence seen in age $25-30 \mathrm{yrs}$ in present study is in prefect agreement with Lee KR et al, Majhi AK et al, Omokanye LO et al and Shetty KS et al studies in which the peak age group was 25-29 yrs. $^{10-13}$ On univariate analysis, the crude risk of ectopic pregnancy increased with age. $26.2 \%$ of cases and $4.6 \%$ controls were in age group 30-34 yrs. From this we found that there is high risk of ectopic pregnancy is in age group 30-34 yrs and it was statistically significant (Odds ratio $[\mathrm{OR}], 7.4 ; 95 \%$ confidence interval [CI], 1.9628.001; P-value $=0.003)$. This correlates well with the following studies conducted in past. Bouyer $\mathrm{J}$ et al found that the risk of ectopic pregnancy increases with age. ${ }^{14}$ The risk of ectopic pregnancy for women of age group 30-34 yrs, 35-39 yrs and $\geq 40$ yrs were 1.3, 1.4 and 2.9 times higher respectively. Parashi $\mathrm{S}$ et al demonstrated that the risk of ectopic pregnancy increases in women over 30 years of age (AOR: 2.45; CI: 0.86-6.97; $\mathrm{P}=0.09) .{ }^{8}$ Existing evidence on how advanced maternal age has an effect on ectopic pregnancy risk remains unclear. It is improbable that the higher risk of ectopic pregnancy in older age cohorts is due to chromosomal abnormalities in the trophoblastic tissue. Some researchers attributed it to some age-related factors, such as: Possible tubal scarring from PID, major gonococcal and chlamydial epidemics and changes in tubal function leading to delay in ovum transport and tubal implantation. However, these hypotheses need to be investigated.

On univariate analysis, in our study low socio-economic status was found as a risk factor for ectopic pregnancy and the association was statistically significant at $\mathrm{P}<.05$ (OR 2.58; CI 1.170-5.692; $\mathrm{P}=0.03$ ). This is supported by Yuk JS and co-workers study which found low socioeconomic status as a risk factor for ectopic pregnancy. ${ }^{15}$ The reason may be because lower socioeconomic status is associated with poor hygienic 
conditions, which predisposes to pelvic inflammatory disease and ectopic pregnancy.

No significant association was found between smoking and ectopic pregnancy in our study. This is in contrary to studies conducted in past. Bouyer $\mathbf{J}$ et al found a strong association between tobacco use and ectopic pregnancy. ${ }^{14}$ Waylen et al revealed that smoking patients demonstrated significantly higher odds of ectopic pregnancy $(\mathrm{OR}=$ 15.69, $95 \%$ CI $=2.87-85.76) .{ }^{16}$ This difference in observation may be due to small number of smokers in study population.

In the present study nulliparity accounts for $35.4 \%$ of the cases which coincides well with studies conducted by Kim $\mathrm{HJ}$ et al and Cornelius $\mathrm{AC}$ et al where nulliparity was observed in $34.6 \%$ and $34.5 \%$ respectively. ${ }^{17,18}$ On univariate analysis it was found that risk of ectopic pregnancy increases with increasing parity. Risk of ectopic pregnancy was 1.5 times more in para 2 (OR 1.46; CI $0.628-3.408 ; \quad \mathrm{P}=0.50)$ but statistically not significant which increases to 10 folds in para $\geq 3$ (OR: 10.17; CI: 1.196-86.546; $\mathrm{P}=0.032$ ) and association was statistically significant. Our finding were similar to the study done by Bouyer $\mathrm{J}$ et al who found a statistically significant association between increasing parity and risk of a subsequent ectopic pregnancy with parity $=2$ (OR:1.6, CI: 1.2-2.0) and parity $\geq 3$ (OR : 2.3, CI: 1.6-3.3) and Cheng $\mathrm{Li}$ et al who observed AOR of 1.14 and 1.58 for para 1 and para $\geq 2$ respectively. ${ }^{14,19}$

On univariate analysis crude OR for prior ectopic pregnancy as risk factor was 5.333 (CI: 0.605-46.981 and P-value $=0.21$ ) which was statistically not significant. Barnhart KT et al indicated that the risk of facing a repeat ectopic pregnancy increases intensely with the number of prior ectopic pregnancy $(\mathrm{OR}=2.98$ for one prior ectopic pregnancy and $\mathrm{OR}=16.04$ for 2 or more). ${ }^{20}$ According to results of study conducted by Moini $\mathrm{A}$ et al, the risk of ectopic pregnancy was almost 17 times higher for women who had prior ectopic pregnancy compared to controls $(\mathrm{OR}=17.165,95 \% \mathrm{CI}=1.89-155.67) .{ }^{9}$ These findings are quite high compared to our study. However, because of the small number of cases with prior ectopic pregnancy history in our study, we could not do a powerful test for a relationship between prior ectopic pregnancy and ectopic pregnancy.

We found a dose-response relation with number of prior spontaneous abortions and ectopic pregnancy. The prevalence of one abortion was $9.2 \%$ in ectopic pregnancy cases and $3.1 \%$ in pregnant controls (OR-3.72, CI: 719-19.237, P-value $=0.19$ ) which is not significant. The prevalence of two or more abortions is $13.9 \%$ in ectopic pregnancy cases and $1.5 \%$ in pregnant controls (OR-11.60, CI-1.368-91.075, $\mathrm{P}$-value=.016) and is statistically significant. This is supported by Bouyer $\mathrm{J}$ et al study in which the adjusted risk of ectopic pregnancy being particularly high in women with two or more previous spontaneous abortions $(\mathrm{AOR}=1.2$ and 3.0 respectively). ${ }^{14}$ Spontaneous abortions may have a causal effect, possibly mediated by infection. However, there may also be common risk factors for ectopic pregnancy and spontaneous abortions, such as chromosomal abnormalities or hormonal factors. The available evidence suggests that the chromosomal abnormalities may be ruled out, but hormonal factors require further study.

In present study, no significant association was found between induced abortion and ectopic pregnancy. The result of our study was similar to that of Moini A et al who observed that $1.2 \%$ of cases and $2.4 \%$ of controls had induced abortions with AOR 0.5 and concluded that induced abortion is not a risk factor for ectopic pregnancy. ${ }^{9}$

$4.62 \%$ cases and $3.08 \%$ controls in present study had previous history of appendicectomy. Brenner PF et al stressed that laparotomy for appendicectomy increases the risk of ectopic pregnancy especially on the right side. ${ }^{21}$ However it was a left sided ectopic pregnancy in all three cases. On statistical analysis, no significant association was found with ectopic pregnancy. This is supported well by Moini A et al study in which women with histories of laparotomy and appendectomy were more likely to have ectopic pregnancy compared with controls. ${ }^{9}$ However, this difference was not statistically significant.

Prior tubal surgeries in the form of tubectomies or recanalization were significant risk factors for ectopic pregnancy. A massive tubal ligation program has definitely increased the risk of pelvic inflammatory disease and in turns that of ectopic pregnancy. Uneven recanalization of the tube forces the fertilized ovum to stay in the tube resulting in ectopic pregnancy. Ectopic pregnancy should be strongly considered if a patient with previous history of tubal surgery presents with acute pain abdomen with or without amenorrhoea or fainting attack.

$12.3 \%$ cases in present study had history of caesarean section prior to ectopic pregnancy. This is quite comparable to that reported by Lee KR et al $13.4 \% .^{22}$ On statistical analysis, no significant association was found with ectopic pregnancy.

In present study, $21.5 \%$ cases had history of D and C or $\mathrm{D}$ and $\mathrm{E}$ which was well supported by Gupta U and coworkers $19.1 \% .^{23}$ On univariate analysis, women with $\mathrm{h} / \mathrm{o}$ $\mathrm{D}$ and $\mathrm{C}$ or $\mathrm{D}$ and $\mathrm{E}$ are at 3 folds increased risk of subsequent EP.

$49.2 \%$ of cases and $12.3 \%$ of controls had history of PID. On univariate analysis, crude OR is 6.9 with CI: $2.850-$ 16.748, $\mathrm{P}<0.001$ which shows statistically significant relation of PID with ectopic pregnancy. Our findings coincides well with Cheng Li et al (2015) ${ }^{19}$ study which shows a significant association between prior PID and ectopic pregnancy (adjusted OR: 6.89; CI:3.29-14.41, 
$\mathrm{P}<0.001)$. Karaer $\mathrm{A}$ et al found that there is high risk of ectopic pregnancy with prior history of pelvic inflammatory disease (AOR for PID s: 6.8 ). ${ }^{24}$

$13.8 \%$ cases and $3.6 \%$ controls had history of prior genital tuberculosis. On univariate analysis, association between prior genital tuberculosis and ectopic pregnancy was found to be nearly significant (Crude OR: 5.06, CI: $1.049-24.429$, P-value $=.059$ ). This is supported well by Sharma JB et al study who observed that genital tuberculosis was responsible for $13.2 \%$ of all cases of ectopic pregnancy. ${ }^{25}$ Higher incidence of genital tuberculosis reported in present study may be because in our country tuberculosis is still a major public health problem.

No association was found between previous use of contraceptive pills and risk of ectopic pregnancy (LNGEC: $\mathrm{OR}=1.355,95 \% \mathrm{CI}: .291-6.310$ and OCPs: $\mathrm{OR}=1.271,95 \% \mathrm{CI}: 0.325-4.963 ; \mathrm{P}=1.0)$. the results were in consistence with that of Zhang $\mathrm{J}$ et al study in which previous use of OCPs did not increase the risk of ectopic pregnancy $(\mathrm{AOR}=0.56){ }^{26}$

$13.85 \%$ cases and $1.54 \%$ controls had h/o previous IUCD use. Our results were comparable with results of Gupta $U$ and co-workers who reported that $12 \%$ had history of previous IUCD use. ${ }^{23}$ The increased use of intra uterine devices as a method of contraception has resulted in the increased incidence of ectopic pregnancies as IUCD is effective in preventing the intra uterine pregnancy but has no protective effect against extra uterine pregnancy. Although the exact mechanism by which implantation is occurring outside the uterus is not well understood, it is thought that IUD-induced inflammation may result in declination of the endosalpinx which delays ovum transport, which leads to ectopic pregnancy. On univariate analysis, previous use of intrauterine device (IUD) was associated with 10 fold increased risk of ectopic pregnancy. This is supported by Parashi $\mathrm{S}$ et al and Moini $\mathrm{A}$ et al studies which found previous use of IUCD as a risk factor for ectopic pregnancy $(A O R=4.79$ and 4.56 respectively). ${ }^{8,9}$

It was observed that with increase in duration of infertility the crude risk for ectopic pregnancy increases.

\section{CONCLUSION}

Various risk factors for ectopic pregnancy identified in our study were pelvic inflammatory disease, tubal ligation, prior spontaneous abortion, age above $30 \mathrm{yrs}$, previous use of IUCD, tubal infertility, low socioeconomic status, prior $\mathrm{D}$ and $\mathrm{C}, \mathrm{D}$ and $\mathrm{E}$ and genital tuberculosis. Increase awareness and knowledge of risk factors will help Obstetricians to suspect and diagnose ectopic pregnancy early \& accurately and enable them to plan medical treatment instead of unnecessary surgical treatment as it affects future fertility of the woman.
The main risk factors of ectopic pregnancy are different in various countries due to various structural, social and cultural characteristics. By identifying risk factors being amenable to modification or prevention, the effective risk-reduction strategies can be devised.

Funding: No funding sources

Conflict of interest: None declared

Ethical approval: The study was approved by the Institutional Ethics Committee

\section{REFERENCES}

1. Farquhar CM. Ectopic pregnancy. Lancet. 2005;366(9485):583-91.

2. Zane SB, Kieke BJ, Kendrick JS, Bruce C. Surveillance in a time of changing health care practices: estimating ectopic pregnancy incidence in the United States. Matern Child Health J. 2002;6(4):227-36.

3. Chow WH, Daling JR, Cates WJ, Greenberg RS. Epidemiology of ectopic pregnancy. Epidemiol Rev. 1987;9:70-94.

4. Walker JJ. Ectopic pregnancy. Clin Obstet Gynecol. 2007;50(1):89-99.

5. Nama V, Manyonda I. Tubal ectopic pregnancy: diagnosis and management. Arch Gynecol Obstet. 2009;279:443.

6. ICMR Task Force Project. J Obst Gynec India. 1990;40(3):425.

7. Pradhan P, Thapamagar SG, Maskey S. A profile of ectopic pregnancy at nepal medical college teaching hospital. Nepal Med Coll J. 2006;8(4):238-42.

8. Parashi S, Moukhah S, Ashrafi M. Main Risk Factors for Ectopic Pregnancy: A Case-Control Study in A Sample of Iranian Women Shayesteh. Int J Fertil Steril. 2014;8(2):147-54.

9. Moini A, Hosseini R, Jahangiri N, Shiva M, Akhoond MR. Risk factors for ectopic pregnancy: a case-control study. J Res Med Sci. 2014;19(9):844-9.

10. Shraddha Shetty K. Clinical Study of Ectopic Pregnancies in a Tertiary care hospital of Mangalore Innovative Journal of Medical and Health Science. 2014;4(1):305-9.

11. Majhi AK, Roy N, Karmakar KS, Banerjee PK. Ectopic pregnancy - an analysis of 180 cases. J Indian Med Assoc. 2007;105(6):308, 310, 312.

12. Omokanye LO, Balogun OR, Salaudeen AG, Olatinwo AW, Saidu R. Ectopic pregnancy in Ilorin, Nigeria: A four year review. Niger Postgrad Med J. 2013;20:341-5

13. Shetty VH, Gowda S, Muralidhar L. Role of ultrasonography in diagnosis of ectopic pregnancy with clinical analysis and management in tertiary centre hospital. J Obstet Gynaecol India. 2014;64(5):354-7

14. Bouyer J, Coste J, Shojaei T, Pouly JL, Fernandez H, Gerbaud L, Job-Spira N. Risk factors for ectopic pregnancy: a comprehensive analysis based on a 
large case-control, population-based study in France. Am J Epidemiol. 2003;157(3):185-94.

15. Yuk JS, Kim YJ, Hur JY, Shin JH. Association between socio-economic status and ectopic pregnancy rate in the Republic of Korea. Int $\mathrm{J}$ Gynaecol Obstet. 2013;122(2):104-7.

16. Waylen AL, Metwally M, Jones GL, Wilkinson AJ, Ledger WL. Effects of cigarette smoking upon clinical outcomes of assisted reproduction: a metaanalysis. Hum Reprod Update. 2009;15(1):31-44.

17. Kim HJ, Cheun SH, Park HE, Yoon BM, Won PK. A clinical study of ectopic pregnancy. Korean J Obstet Gynecol. 2003;46(10):2022-7.

18. Cornelius AC, Onyegbule A, Onyema U, Chenna ET, Duke OA. A five year review of ectopic pregnancy at Federal Medial Centre, Owervi, South East, Nigeria. Niger J Med. 2014;23(3):207-12.

19. Cheng Li, Zhao WH, Zhu Q, Cao SJ, Ping H, Xi X. Risk factors for ectopic pregnancy: a multi-center case-control study. BMC Pregnancy Childbirth. 2015;15:187.

20. Barnhart KT, Sammel MD, Gracia CR, Chittams J, Hummel AC, Shaunik A. Risk factors for ectopic pregnancy in women with symptomatic firsttrimester pregnancies. Fertil Steril. 2006;86:36-43.

21. Brenner PF, Roy S, Daniel R, Mishell. A study of 300 consecutive surgically treated cases. JAMA. 1980;243(7):673-6.
22. Lee KR, Lee JS, Kim HJ, Kim JH, Lee MS, Song IC. A clinical study of ectopic pregnancy. Korean $\mathbf{J}$ Obstet Gynecol, 2001.

23. Gupta U, Sharma P. Ectopic pregnancy - A prospective analysis of 100 cases. Obstet Gynec India. 1992;42:597-600.

24. Karaer A, Avsar FA, Batioglu S. Risk factors for ectopic pregnancy: a case-control study. Aust N Z J Obstet Gynaecol. 2006;46(6):521-7.

25. Sharma JB, Naha M, Kumar S, Roy KK, Singh N, Arora R. Gestational Tuberculosis: an important cause of ectopic pregnancy in India. Indian J Tuberc. 2014;61(4):312-7.

26. Zhang J, Li C, Zhao WH, Xi X, Cao SJ, Ping H. Association between levonorgestrel emergency contraception and the risk of ectopic pregnancy: a multicenter case-control study. Sci Rep. 2015;5:8487.

Cite this article as: Khedar S, Mital P, Rajoria L, Gupta D, Shekhawat U, Singhal S. A case-control study to evaluate risk factors for ectopic pregnancy. Int J Reprod Contracept Obstet Gynecol 2016;5:2828-35. 